\title{
Exploring the associations of depressive symptoms with healthy eating self-efficacy over time amongst women in the READI cohort study
}

Rachelle Opie ${ }^{*} \mathbb{0}$, Gavin Abbott, David Crawford and Kylie Ball

\begin{abstract}
Background: There is growing evidence that diet is associated with both depressive symptoms and clinical depression, likely through biological mechanisms. However, it is also plausible that depression impacts diet, for example by impairing the personal drivers of healthy eating behaviors such as self-efficacy. This study is one of the first to explore the association of depressive symptoms with healthy eating self-efficacy over time.

Methods: Data was drawn from the Resilience for Eating and Activity Despite Inequality (READI) longitudinal study, a prospective cohort study of socioeconomically disadvantaged Australian women. This analysis includes a sub-sample of 1264 women. Linear mixed models, with random intercepts for suburb of residence, were performed to explore the relationships between total healthy eating self-efficacy at 5-years follow-up and depressive symptoms over time, whilst adjusting for potential confounders. To assess different trajectories of depressive symptoms over time, four categories were created; 1 . no depressive symptoms $(n=667)$, 2. resolved depressive symptoms $(n=165)$, 3. new depressive symptoms ( $n=189)$, and 4. persistent depressive symptoms $(n=243)$.
\end{abstract}

Results: There was very strong evidence of a difference in total healthy eating self-efficacy at follow-up between the four depressive symptoms trajectory categories $(F(3,235)=7.06, p<.0001)$, after adjusting for potential confounders. Pairwise comparisons indicated strong evidence of higher healthy eating self-efficacy among individuals with no depressive symptoms compared to individuals with persistent depressive symptoms ( $\mathrm{B}=1.97[95 \% \mathrm{Cl}: 0.60,3.33], p=.005)$. Similarly, there was evidence of higher healthy eating self-efficacy in individuals with resolved depressive symptoms than those with persistent depressive symptoms ( $\mathrm{B}=1.95[95 \% \mathrm{Cl}: 0.18,3.72], p=.031)$.

Conclusions: This study provides new insights demonstrating differences in total healthy eating self-efficacy at 5-year follow-up according to trajectory of depressive symptoms over time. Future interventions should focus on strategies that enhance self-efficacy among individuals with or at risk of depressive symptoms for supporting healthier dietary practices, which in turn, may contribute to reducing the highly burdensome mental health condition.

Keywords: Healthy eating, Diet, Depression, Depressive symptoms, Self-efficacy, Women, Socioeconomic disadvantage

*Correspondence: rachelle.opie@deakin.edu.au

Institute for Physical Activity and Nutrition, School of Exercise and Nutrition Sciences, Faculty of Health, Deakin University, 221 Burwood Highway, Burwood, VIC 3125, Australia

\section{Background}

Depression is a common illness, with more than 264 million people of all ages affected globally [1]. It is a leading cause of disability worldwide, and the burden original author(s) and the source, provide a link to the Creative Commons licence, and indicate if changes were made. The images or other third party material in this article are included in the article's Creative Commons licence, unless indicated otherwise in a credit line to the material. If material is not included in the article's Creative Commons licence and your intended use is not permitted by statutory regulation or exceeds the permitted use, you will need to obtain permission directly from the copyright holder. To view a copy of this licence, visit http://creativecommons.org/licenses/by/4.0/. The Creative Commons Public Domain Dedication waiver (http://creativeco mmons.org/publicdomain/zero/1.0/) applies to the data made available in this article, unless otherwise stated in a credit line to the data. 
of depression is on the rise [2]. There are effective psychological and pharmacological treatments for moderate and severe depression, yet non-adherence to antidepressant treatment is very common [3, 4]. Lifestyle options are commonly more well-accepted than pharmacological treatment approaches by patients [5], and there is growing evidence that diet is associated with both depressive symptoms and clinical depression [6]. Typically, it is assumed that diet and depression are related through biological mechanisms including inflammation, oxidative stress, gastro-intestinal microbiota and neurotrophic factors $[7,8]$. However, it is also plausible that depression impacts diet, for example by impairing the personal drivers of healthy eating behaviors [9]. One of the most consistently observed personal drivers of healthy eating is self-efficacy. Self-efficacy refers to a person's perceived beliefs about their capabilities to produce a desired action or exercise influence over events that affect their lives [10] e.g., an individuals' confidence in their ability to make the behavior changes necessary to achieving their goals [10]. Selfefficacy beliefs affect life choices, level of motivation, quality of functioning, resilience to adversity and vulnerability to stress and depression [10, 11]. Dietary/ healthy eating self-efficacy refers to the perceived capability to make healthy food choices, even when faced with potential barriers [12]. Increasing self-efficacy may lead to healthy eating behavior change. For example, higher dietary self-efficacy has been shown to be associated with higher intakes of fruit and vegetables [13], calcium-rich foods [14] and lower intakes of fat [15]. Conversely, lower self-efficacy beliefs are related to unhealthy food intake [16].

Studies examining the relationship between general self-efficacy and depression have found that individuals with more serious symptoms of depression at baseline report poorer general self-efficacy at follow-up [17]. However, few studies [17-19] have assessed associations of depression with healthy eating self-efficacy, and fewer have examined this over time. For example, a secondary data analysis (using cross-sectional baseline data) of 743 women who were participating in a workplace wellness RCT, found that depressive symptoms were associated with decreased healthy eating self-efficacy, as well as more frequent emotional eating [18]. Additionally, in a cohort study of 18 year-old Australian men $(n=301)$ and women $(n=282)$, depression scores were inversely cross-sectionally associated with confidence in being able to stick to a healthy diet [19]. Finally, greater depressive symptoms were correlated with reports of poorer dietary intent and choice, less perceived support for healthy eating, and poorer self-efficacy for diet in 198 urban youth at risk for developing type 2 diabetes mellitus [20].
While these limited cross-sectional findings suggest a link between depressive symptoms and healthy eating self-efficacy, further research using prospective study designs is required to establish the temporal nature of associations identified. Hence, the aim of this study was to explore the associations of depressive symptoms with healthy eating self-efficacy over time. This is important because if depressive symptoms are linked to reduced self-efficacy, dietary interventions for people with, or at risk of depression, may need to focus intensively on enhancing self-efficacy for healthy eating.

More specifically, this study explores the association of depressive symptoms with healthy eating self-efficacy over time (from baseline (T1) to 5 years follow-up (T3)) amongst women living in socioeconomically disadvantaged neighborhoods in Australia. This is an important sample in which to assess the associations of depressive symptoms with healthy eating self-efficacy, given that women are at significantly greater risk of depression than men [21], and that both depression and unhealthy eating behaviors are more prevalent in socioeconomically disadvantaged neighborhoods [22, 23].

\section{Methods \\ Study sample}

Data was drawn from the Resilience for Eating and Activity Despite Inequality (READI) longitudinal study, a prospective cohort study of 4349 women aged 18-46years recruited randomly using the electoral roll from 80 socioeconomically disadvantaged urban and rural neighborhoods of Victoria, Australia. The aims of the READI study were to investigate pathways (personal, social and structural) by which socio-economic disadvantage influences lifestyle choices associated with obesity risk (physical inactivity, poor dietary choices), and to explore mechanisms underlying 'resilience' to obesity risk in socioeconomically disadvantaged women and children. Detailed methods are provided elsewhere [24]. The study was approved by the Deakin University Human Research Ethics Committee. Women provided written, informed consent to participate.

In late 2007 and early 2008, a total of 4934 women (45\% response rate) completed a mailed survey at baseline. Of those that responded, 585 women were excluded for reasons specified in Fig. 1 . Thus, 4349 women remained who were eligible to participate (e.g., resided in 'READI' neighborhoods, were within the valid age range (between 18 and 45 years), and did not have missing data). Of this cohort, those who consented to further follow-up and remained eligible ( $n=3019$ women) were re-contacted to complete a follow-up survey 3 years after the baseline survey (2010-11). This survey was completed by 1913 women (44\% of initial cohort). A further follow-up 


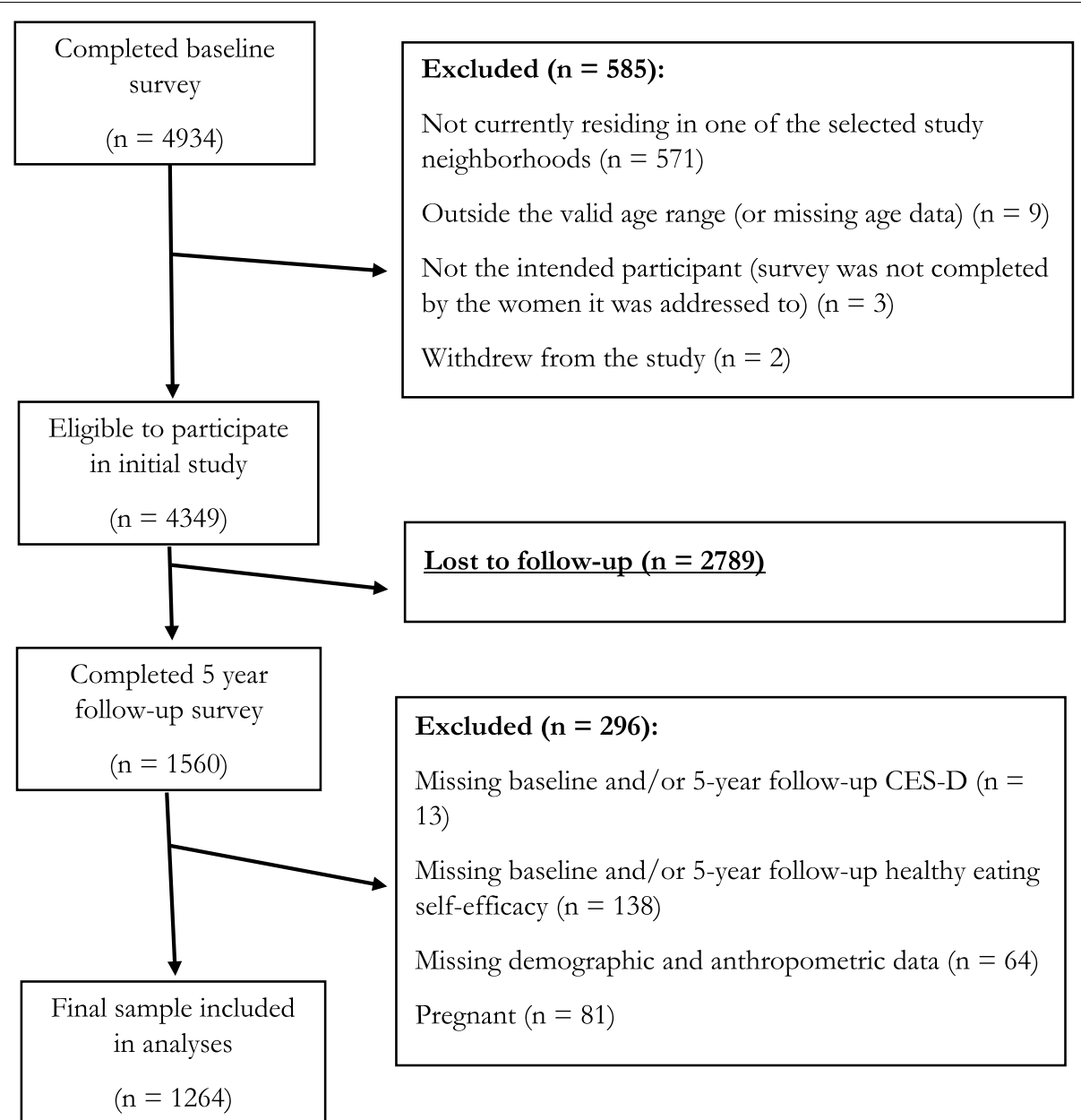

Fig. 1 Flowchart of inclusion and exclusion into the study

survey 5 years after the baseline survey (2012-13) was completed by 1560 women (36\% of initial cohort).

Women who did not complete questions on depressive symptoms, healthy eating self-efficacy score, or who had missing demographic or anthropometric data at baseline or 5-year follow-up were excluded. Additionally, because dietary behaviors typically alter in pregnancy [25], and are therefore not reflective of habitual intake, pregnant women (at any time point) were not included. Thus, of the total possible baseline and 5 year follow-up completers $(n=1560), 1264$ women remained in the study for analyses (29\% of initial cohort). Refer to Fig. 1 for flowchart of inclusion and exclusion into the study.

\section{Healthy eating self-efficacy measures}

At baseline and 5 years follow-up, a 17-item self-efficacy scale [25] was used to assess individuals' confidence in performing a number of food related activities, such as procuring ("How confident are you that you could shop regularly for healthy nutritious foods over the next year"), preparing (“...prepare/cook healthy nutritious foods”), and eating healthy foods (e.g., "...eat enough fruit and vegetables for good health"), and limiting consumption of less healthy options (e.g., "limit your fast food consumption to once a week or less"). Additionally, the scale assessed individuals' confidence for making healthy food choices ("stick to low-fat healthy foods") according to social or environmental factors (e.g., "when eating with friends or co-workers"; "when you are eating out"; "when you are alone and there is no one to watch you"; "when there are high-fat foods available"), and emotional situations (e.g., "when you feel depressed, bored or tense"; "when you are craving less healthy foods"; "when you feel too tired or lazy"). This scale was adapted from an existing self-efficacy scale for health-related diet behaviors developed by Sallis et al., which has demonstrated internal consistency reliabilities and criterion-related validity [25]. Responses were provided via a 5-point Likert scale ranging from 1 "not at all to 5 "extremely confident". In the present study, three items were omitted from analysis 
a priori, because they were either not applicable to a broad number of women ("stick to low-fat healthy foods even when you are eating at work/ place of study") or they were not well-aligned with the overarching themes relating to procuring, preparing, social / environment factors, or emotional situations (e.g., "not eat meals while watching TV", "not eat snacks while watching TV"). In addition to considering the individual items of the scale, in order to gain insights into important specific components of self-efficacy, we also calculated a single composite score by summing responses across 14 items. The total score ranged from 14 to 70 , with a higher score indicating greater confidence. Cronbach alpha coefficients for the total healthy eating self-efficacy scale were 0.95 at both baseline and 5 years follow-up, indicating high internal consistency.

\section{Depressive symptoms measure}

Depressive symptoms were assessed using the 10-item Center for Epidemiologic Studies Depression Scale (CESD) [26] at baseline and 5 years follow-up. This scale is a commonly-used self-reported measure of depressive symptoms with good retest reliability and predictive validity compared with the original 20 -item version [2630]. Responses were reported using a four-point Likert scale ranging from 'rarely' (scored 0 ) to 'most of the time' (scored 3). The total score was derived by calculating the sum of 10 items (possible scores range from 0 to 30), with higher scores indicating a higher presence of depressive symptoms. Depressive symptoms were presented as a dichotomous variable with a CES-D score of $\geq 10$ used to define risk of heightened depressive symptoms. This cut-off value has been shown to produce good testretest reliability $[26,28]$. Additionally, in order to assess different trajectories of depressive symptoms over time, the following four categories were created; Group 1 no depressive symptoms (CES-D $<10$ at $\mathrm{T} 1$ and $\mathrm{T} 3$ ), Group 2 resolved depressive symptoms (CES-D $\geq 10$ at $\mathrm{T} 1$, but $\mathrm{CES}<10$ at T3), Group 3 new depressive symptoms (CES $<10$ at T1, but CES-D $\geq 10$ at T3), and Group 4 persistent depressive symptoms (CES-D $\geq 10$ at $\mathrm{T} 1$ and $\mathrm{T} 3$ ).

\section{Statistical analysis}

Data was analysed using the Statistical Package for the Social Sciences (SPSS) version 26 [31]. P-values <.001 were deemed to indicate very strong evidence (against the null hypothesis), $p$-values $<.01$ indicated strong evidence, $p$-values $<.05$ indicated some evidence, $p$-values $<.1$ indicated little evidence, and $p$-values $\geq .1$ indicated insufficient evidence [32]. Baseline characteristics of the final eligible sub-sample included in this analysis $(n=1264)$ were compared to those of the remaining (excluded) READI sample $(n=3085)$. When comparing the two groups Chi-square tests were used for categorical variables and independent samples t-tests were performed for continuous variables.

\section{Longitudinal associations between healthy eating self-efficacy and depressive symptoms}

Linear mixed models, with random intercepts for suburb of residence, were performed to explore the relationships between 1 . Total healthy eating self-efficacy score and individual items at 5-years follow-up (continuous, dependant variables) according to baseline depression risk (categorical, independent variable), and 2. Total healthy eating self-efficacy score at 5 years follow-up (continuous, dependant variable) and depressive symptoms over time (categorical, independent variable). Unadjusted models were fitted as well as models adjusting for the baseline level of the healthy eating self-efficacy outcome plus a number of potential confounders selected a-priori based on existing evidence that these variables are likely to play a role in diet / self-efficacy for healthy eating and depressive symptoms. All confounders were measured at baseline, and were as follows: age (continuous); highest education level (low (less than high school), medium (high school/trade/diploma), high (tertiary)); country of birth (Australia, overseas); employment status (full-time, part-time, not currently employed); relationship status (married/de facto, separated/ divorced/ widowed, never married); location of residence (urban, rural); smoking status (never smoked, former smoker, occasional smoker, regular smoker); BMI (based on selfreported height and weight), and leisure-time physical activity, assessed using the International Physical Activity Questionnaire (IPAQ) [33]. Total leisure time physical activity represented the weekly sum of the self-reported number of minutes spent in vigorous- and moderateintensity leisure-time physical, and walking for leisure.

An additional analysis was conducted to examine associations between concurrent changes in total healthy eating self-efficacy (continuous dependent variable) and depressive symptoms (continuous independent variable) over time. Fixed-effects models, with repeated measures across participants using data from all three timepoints (baseline, 3-year follow-up, and 5-year follow-up), were fitted with cluster-robust standard errors [34] to account for clustering of participants within suburbs. In this model, any participants with data for two or more time points contributed to the effect estimate. As participants serve as their own control in fixed-effects models, there is no confounding by time-invariant factors, however as confounding can occur for time-varying factors [35], participant age and BMI were included in the model as timevarying covariates. 


\section{Sensitivity analysis}

It was considered that some participants might have a relatively small increase or decrease (e.g., one or two points) in the depressive symptoms score from baseline to 5-year follow-up, which may be considered a clinically insignificant difference and plausibly due to measurement error, and yet have crossed over from low (CESD10 score of $<10)$ to high $(\geq 10)$ risk of depression (or vice-versa) between time points. As a sensitivity analysis, the longitudinal linear mixed model testing the association between total healthy eating self-efficacy score at 5 -year follow up and depressive symptoms over time was re-run, excluding any individuals who had a CES-D score change of $\pm 1-2$ points, crossed over the cut-off / threshold value for depressive symptoms $(C E S-D \geq$ or $<10)$, and were classified as either new depressive symptoms or resolved depressive symptoms in the primary analysis.

\section{Results}

Comparing the final eligible sub-sample $(n=1264)$ and the excluded READI sub-sample $(n=3085)$, the eligible sub-sample participants had lower mean CES-D scores at baseline $($ mean $=7.9[\mathrm{SD}=5.4]$ vs. mean $=8.5$ $[S D=5.6]$ )and were less likely to be at high risk for depression, were older, and were more likely to be Australian born, married, reside in a rural setting, and have completed tertiary education (Table 1). Additionally, the eligible sub-sample participants were less likely to be unemployed or smoke compared to the excluded sub-sample. There was little evidence of group differences for healthy eating self-efficacy, BMI, or leisure time physical activity.

At baseline, the mean value for the total healthy eating self-efficacy score was $44.9(\mathrm{SD} \pm 10.9)$, with a large

Table 1 Baseline characteristics of the final eligible sub-sample included in this analysis compared to the excluded READI sample

\begin{tabular}{|c|c|c|c|}
\hline & $\begin{array}{l}\text { Included eligible sub-sample } \\
(n=1264)\end{array}$ & $\begin{array}{l}\text { Excluded READI sub-sample } \\
(n=3085)\end{array}$ & $p$-value \\
\hline Depression (CES-D), mean (SD) & $7.9(5.4)$ & $8.5(5.6)$ & $<.0001$ \\
\hline High risk for depression (CES-D $\geq 10), \%$ (n) & $32.3(408)$ & $38.6(1167)$ & $<.001$ \\
\hline Total healthy eating self-efficacy, mean (SD) & $44.8(10.9)$ & $44.2(11.3)$ & .072 \\
\hline Age, mean (SD) & $36.8(7.5)$ & $33.5(8.2)$ & $<.0001$ \\
\hline \multicolumn{4}{|l|}{ Highest education level, \% (n) } \\
\hline Low (less than high school) & $22.6(285)$ & $21.9(661)$ & \multirow[t]{3}{*}{.001} \\
\hline Medium (high school/trade/diploma) & $47.7(600)$ & $53.5(1616)$ & \\
\hline High (tertiary) & $29.7(374)$ & $24.7(746)$ & \\
\hline Born in Australia, \% (n) & $91.9(1162)$ & $87.7(2689)$ & $<.0001$ \\
\hline \multicolumn{4}{|l|}{ Employment status, \% (n) } \\
\hline Full-time & $36.2(451)$ & $38.9(1162)$ & \multirow[t]{3}{*}{$<.0001$} \\
\hline Part-time & $34.1(425)$ & $27.5(820)$ & \\
\hline Not currently employed & $29.6(369)$ & $33.6(1003)$ & \\
\hline \multicolumn{4}{|l|}{ Relationship status, \% (n) } \\
\hline Married/de facto & $71.4(902)$ & $63.0(1927)$ & \multirow[t]{3}{*}{$<.0001$} \\
\hline Separated/ divorced/ widowed & $7.8(99)$ & $8.9(271)$ & \\
\hline Never married & $20.7(262)$ & $28.1(861)$ & \\
\hline \multicolumn{4}{|l|}{ Area of residence, \% (n) } \\
\hline Urban & $41.1(520)$ & $48.5(1496)$ & \multirow[t]{2}{*}{$<.0001$} \\
\hline Rural & $58.9(744)$ & $51.5(1589)$ & \\
\hline \multicolumn{4}{|l|}{ Smoking status, \% (n) } \\
\hline Never smoked & $51.7(654)$ & $49.6(1530)$ & \multirow[t]{3}{*}{.001} \\
\hline Former smoker & $27.1(342)$ & $23.5(724)$ & \\
\hline Current smoker & $21.2(268)$ & $26.9(828)$ & \\
\hline \multicolumn{4}{|l|}{ BMI categorised $^{\mathrm{a}}, \%(\mathrm{n})$} \\
\hline Under/healthy weight & $53.8(655)$ & $52.3(1498)$ & \multirow[t]{3}{*}{652} \\
\hline Overweight & $25.1(306)$ & $25.5(731)$ & \\
\hline Obese & $21.1(257)$ & $22.2(635)$ & \\
\hline $\begin{array}{l}\text { Leisure time physical activity (total minutes per week), mean } \\
\text { (SD) }\end{array}$ & $210.1(269.7)$ & $211.8(323.4)$ & .856 \\
\hline
\end{tabular}

${ }^{\mathrm{a}} \mathrm{BMI}$ categorised as under/healthy weight, overweight, obese according to WHO cut-points [36] 
range in scores from 16 to 70 , and at 5 -years follow-up the mean score was 45.6 ( $\mathrm{SD} \pm 11.4$; range 14 to 70 ). Table 2 details the mean depressive symptom scores for the four depressive symptom trajectory categories.

\section{Healthy eating self-efficacy at 5-year follow-up according to baseline depression risk}

In the adjusted model, there was virtually no evidence of a difference in total healthy eating self-efficacy at 5-year follow-up among individuals with baseline low risk for depression $(C E S-D<10)$ compared to individuals with high risk for depression (CES-D $\geq 10$ ) (Table 3). For the individual self-efficacy items, there was evidence of higher healthy eating self-efficacy at 5 -year follow-up for shopping regularly for healthy nutritious foods $(\beta=0.15$ [95\% CI:0.05,0.26], $p=.004$ ), preparing/cooking healthy nutritious foods ( $\beta=0.11$ [95\% CI:0.01,0.22], $p=.030$ ), and eating enough vegetables for good health $(\beta=0.11$ [95\% CI:0.01,0.21], $p=.038$ ), among women with low risk for depression at baseline compared to high risk individuals (adjusted models). There was little to no evidence of differences between the two groups for the remaining healthy eating self-efficacy items.

Unadjusted model. Estimated mean differences from mixed-effects linear models with random intercepts for suburbs.

Adjusted model. Estimated mean differences from mixed-effects linear models with random intercepts for suburbs and adjusted for baseline healthy eating self-efficacy, age, education, country of birth, employment, marital status, area of residence, smoking status, leisure time physical activity, and BMI.

\section{Healthy eating self-efficacy and depressive symptoms over time}

There was very strong evidence of a difference in total healthy eating self-efficacy at 5-year follow-up between the four depressive symptoms trajectory categories $(\mathrm{F}(3,235)=7.06, p<.0001)$, while adjusting for potential

Table 2 Mean (SD) depressive symptom scores for each depressive symptoms trajectory category at baseline and follow-up

\begin{tabular}{llll}
\hline $\begin{array}{l}\text { Depressive symptoms } \\
\text { trajectory category }\end{array}$ & $\mathbf{n}$ & $\begin{array}{l}\text { Baseline } \\
\text { CES-D } \\
\text { Mean (SD) }\end{array}$ & $\begin{array}{l}\text { 5-Year } \\
\text { Follow-Up } \\
\text { CES-D } \\
\text { Mean (SD) }\end{array}$ \\
\hline No depressive symptoms & 667 & $4.5(2.5)$ & $4.5(2.4)$ \\
Resolved depressive symptoms & 165 & $13.3(3.4)$ & $6.0(2.3)$ \\
New depressive symptoms & 189 & $5.9(2.3)$ & $13.7(3.8)$ \\
Persistent depressive symptoms & 243 & $14.8(4.3)$ & $15.1(4.2)$ \\
\hline
\end{tabular}

confounders. Pairwise comparisons indicated strong evidence of higher healthy eating self-efficacy among individuals with no depressive symptoms $(n=667)$ compared to individuals with persistent depressive symptoms ( $n=243)$ (estimated mean difference B $=1.97$ [95\% CI: $0.60,3.33$ ], $p=.005$ ). Similarly, there was evidence of higher healthy eating self-efficacy in individuals with resolved depressive symptoms $(n=165)$ than those with persistent depressive symptoms $(\mathrm{B}=1.95$ [95\% CI: 0.18 , $3.72], p=.031$ ).

In the fixed-effects model, there was very strong evidence for an association between concurrent change in depressive symptoms and total healthy eating self-efficacy $(\mathrm{B}=-0.15$ [95\% CI: $-0.23,-0.07], p<.0005)$, indicating that for a one-unit within-individual change in CES-D score there was an average decrease in healthy eating self-efficacy score of 0.15 .

\section{Sensitivity analysis}

Seventeen individuals with resolved depressive symptoms $(10 \%$, total $n=165)$ and 15 individuals with new depressive symptoms $(8 \%$, total $n=189)$ reported a CES-D score change of $\pm 1-2$ points, and crossed over the cut-off / threshold value for depressive symptoms $(C E S-D \geq$ or $<10)$. As a sensitivity analysis, the linear mixed model examining associations between total healthy eating self-efficacy score and depressive symptoms trajectory category was re-run excluding these 32 individuals, and the results remained generally consistent with the primary analysis (data not shown).

\section{Discussion}

This is one of the first studies to explore the relationship between self-efficacy for healthy eating and depressive symptoms over time. It provides new insights demonstrating differences in total healthy eating self-efficacy at 5-year follow-up according to trajectory of depressive symptoms over time. Specifically, healthy eating selfefficacy scores were found to be higher among individuals who reported no depressive symptoms over time, and among individuals with resolved depressive symptoms at 5-year follow-up, compared to individuals with persistent depressive symptoms. Women with baseline low risk for depression had higher healthy eating self-efficacy at 5-year follow-up for shopping, and preparing/cooking healthy nutritious foods, and eating enough vegetables for good health, compared to those at high risk for depression. Additionally, the fixed-effects model demonstrated evidence of an association, such that as depressive symptoms increased over time, self-efficacy for healthy eating decreased (and vice-versa).

Self-efficacy is defined as an individuals' confidence in their ability to make the behavior changes necessary 
Table 3 Healthy eating self-efficacy scores at 5-year follow-up according to baseline depression risk

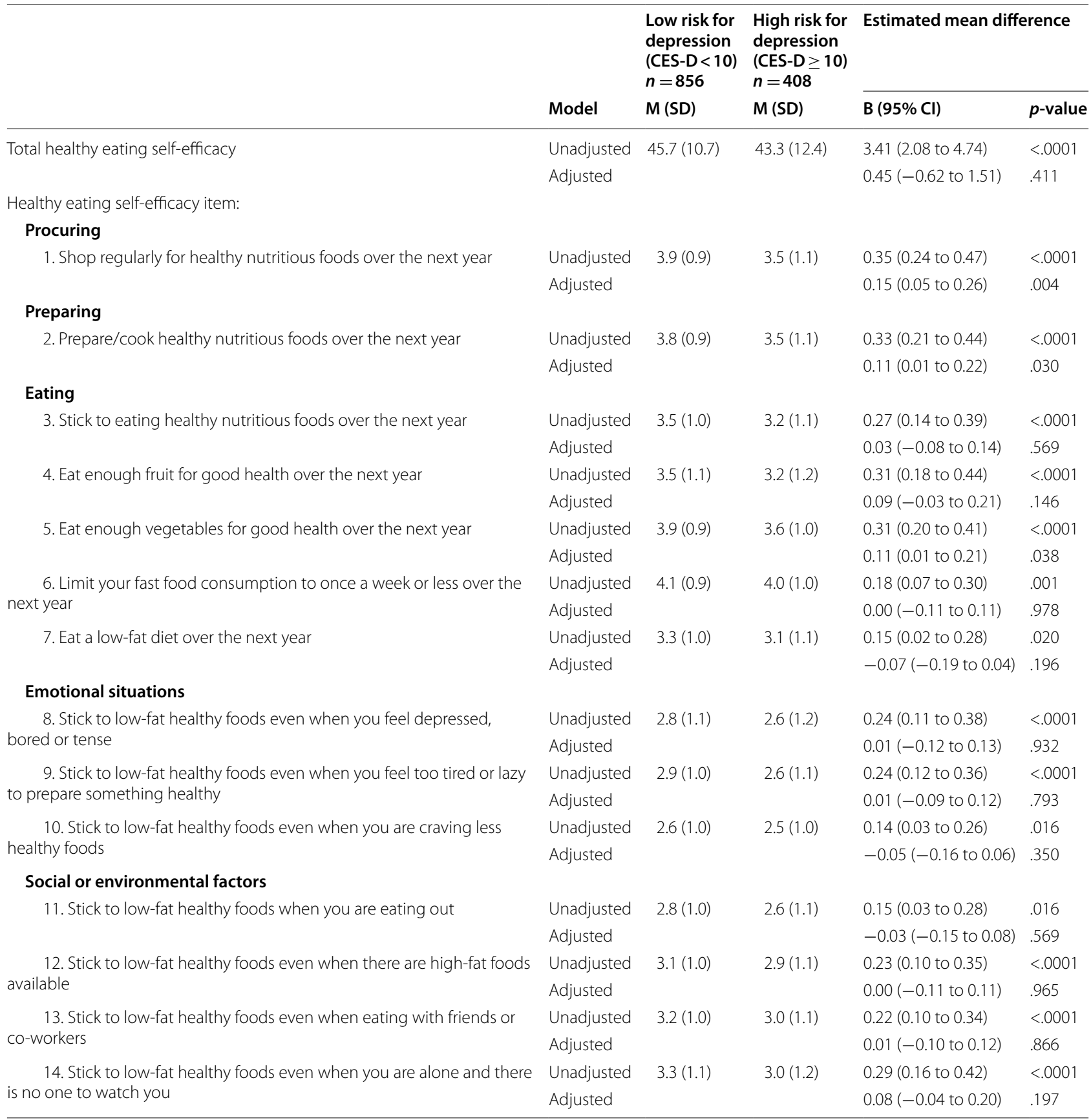

to achieving their goals [11], and has been associated with the adoption of and engagement in many nutrition and health behaviors, including changes in weight and weight-related behaviors [37]. Hence, it is worth considering that the association between healthy eating self-efficacy and depression may be bidirectional. For example, enhancing self-efficacy has been viewed as an important strategy for promoting improvements in dietary intake
[37], because higher self-efficacy has been associated with a healthy dietary pattern [16] [38], which in turn may be associated with reduced risk of depression [39]. On the other hand, self-efficacy is commonly diminished in depressed individuals [40], and the varying trajectories of mental illness means motivation and self-efficacy can be impaired or fluctuate, which in turn may lead to poor eating behaviors [18] and poor adherence to dietary 
recommendations [41]. This is consistent with findings from our study, where individuals at high risk for depression had lower healthy eating self-efficacy for procuring, preparing, cooking and eating healthy foods.

To further compound this, common side effects of lowered mood and depression include changes in appetite, which can involve either a reduced interest in food or an increase appetite with cravings for less healthy choices like sweet, salty and fatty foods [42-44]. Depression can also be commonly associated with fatigue and apathy, which may impact on an individual's motivation to engage in healthy dietary habits [45], and reduced energy for grocery shopping, meal preparation, cooking, and clean-up [43, 46-49]. As a result of decreased concentration, decreased mental endurance and slowed thinking [49] individuals may also find learning new recipes or developing cooking skills challenging [47, 48]. Our earlier analysis of adherence to the Australian Dietary Guidelines amongst the READI cohort, similarly showed that baseline diet quality was poorer amongst individuals with depressive symptoms at follow-up, compared to individuals without depressive symptoms [50]. When considering that a healthy dietary pattern (high in vegetables, fruits, whole grains, fish, and legumes) is associated with a decreased risk of depression, [6,51], and that an unhealthy dietary pattern (high in processed foods, refined grains, and sweets) may increase the risk of depression [6,51], the current findings suggest the importance of the development of strategies to promote self-efficacy among individuals with /or at risk of depressive symptoms.

Goal setting, problem solving (e.g., meal planning, recipe modification), and provision of personalised feedback can help individuals increase their self-efficacy for changes in their eating behavior [37, 52]. Furthermore, learning basic cooking skills and hands-on learning of healthy recipes is empowering and has previously been associated with healthier food choices [52]. This relates to food literacy, an important tool needed to support a healthy lifelong relationship with food - it empowers individuals to achieve optimal diet quality through skills and behaviors required to plan, manage, select, prepare, and eat food to meet needs [53]. Motivational interviewing and health coaching, which foster good communication and therapeutic relationships, are likely integral intervention components for improving self-efficacy and dietary adherence [54]. Future studies could test the efficacy of all of these components for promoting enhanced dietary self-efficacy and healthy eating amongst people at risk of or experiencing depression.

\section{Limitations and strengths}

A potential study limitation is that only $29 \%$ of the original READI sample were eligible for analysis in the present study. However, this attrition rate of $71 \%$ at 5 -year follow-up is noteworthy when considering that other longitudinal community-based nutrition research among women report considerable range in attrition rates from 43 to $75 \%$ [55]. The proportion of women reporting depressive symptoms ( $32 \%, n=408$ out of 1264) in our cohort were higher than that of the Australian population-based National Health Survey [56], although the latter was based on an assessment of women's selfreported "depression or feelings of depression" rather than on a multi-item symptom scale, which could at least partly account for the difference. Moreover, there was a reported difference in the \% at high risk for depression among the included (32.3\%) and excluded (38.6\%) participants in our study, which may limit generalisability. The READI study sample was recruited from disadvantaged neighborhoods and hence generalisability to other samples may be limited; although our eligible sub-sample were of a slightly higher socioeconomic position than the remaining READI sample. Pregnant women were excluded from this study, which may also limit generalisability of findings. Future studies should be conducted in this population group, as perinatal depression (from conception to the end of the first year of a child's life) has a high global prevalence [57], poses significant costs to individuals, families and society, and has shown to be associated with poorer dietary quality [58].

Depressive symptoms were assessed using the CES-D, a commonly-used self-reported measure, with a cut-off score (e.g., 10 or greater) that aids in identifying individuals at risk for clinical depression, with good sensitivity, specificity and high internal consistency [26, 59], and is able to identify individuals with significant depression with good precision [60]. In this analysis, the CES-D was presented as a categorical variable, rather than a continuous variable, which is useful for comparing low/high risk groups, but may have resulted in some women being categorised as changing trajectory on the basis of a very small change in score. To address this, we conducted a sensitivity analysis, and the results remained generally consistent with those of the primary analysis. A major strength of this study is the use of longitudinal data to explore the associations between depressive symptoms over time with healthy eating self-efficacy, which to our knowledge has not been performed before. Finally, due to the large sample size we were also able to control for relevant confounders. 


\section{Conclusion}

This study provides new insights demonstrating that depressive symptoms, as well as symptom trajectory over time, are associated with self-efficacy for healthy eating among women living in socioeconomically disadvantaged neighborhoods in Australia. Future interventions should focus on strategies that enhance self-efficacy among individuals with or at risk of depressive symptoms for supporting healthier dietary practices and improving dietary adherence. This in turn, may help improve dietary intakes and contribute to reducing this highly burdensome mental health condition.

\section{Abbreviations}

CES-D: Center for Epidemiologic Studies Depression Scale; READI: Resilience for Eating and Activity Despite Inequality; SPSS: Statistical Package for the Social Sciences.

\section{Acknowledgements}

Not applicable.

\section{Authors' contributions}

RSO analyzed and interpreted the data (under guidance from GA), and RSO was a major contributor in writing the manuscript. All authors interpreted the data, contributed to draft versions, read and approved the final manuscript.

\section{Funding}

The READI study was funded by a National Health and Medical Research Council (NHMRC) Strategic Award, ID 374241. The funding body had no role in study design, collection, analysis and interpretation of the data, and in writing the manuscript.

\section{Availability of data and materials}

The datasets used and/or analysed during the current study are available from the last author (KB) on reasonable request.

\section{Declarations}

\section{Ethics approval and consent to participate}

The study was approved by the Deakin University Human Research Ethics Committee (ethics approval number 91-2006). Women provided written, informed consent to participate.

\section{Consent for publication}

Not applicable.

\section{Competing interests}

The authors declare that they have no competing interests.

Received: 27 October 2020 Accepted: 29 November 2021

Published online: 18 December 2021

\section{References}

1. Global Burden of Disease Study Collaborators. Health effects of dietary risks in 195 countries, 1990-2017: a systematic analysis for the global burden of disease study 2017. Lancet. 2019:393(10184):1958-72.

2. World Health Organization (WHO). Depression. 2020. https://www.who. int/news-room/fact-sheets/detail/depression. Accessed 13 July 2020.

3. Wang PS, Aguilar-Gaxiola S, Alonso J, Angermeyer MC, Borges G, Bromet EJ. Worldwide use of mental health services for anxiety, mood, and substance disorders: results from 17 countries in the WHO world mental health (WMH) surveys. Lancet. 2007;8(370):841-50
4. Pampallona S, Bollini P, Tibaldi G, Kupelnick B, Munizza C. Patient adherence in the treatment of depression. Br J Psychiatry. 2002;180:104-9.

5. $\mathrm{Ng} \mathrm{CHC,} \mathrm{Ng} \mathrm{Y.} \mathrm{Managing} \mathrm{depression} \mathrm{in} \mathrm{primary} \mathrm{care.} \mathrm{Singap} \mathrm{Med} \mathrm{J.}$ 2017;58(8):459-66.

6. Ljungberg TBE, Lethin C. Evidence of the importance of dietary habits regarding depressive symptoms and depression. Int J Environ Res Public Health. 2020;17:1616.

7. Marx WMG, Berk M, Jacka F. Psychiatry: the present state of the evidence. Proc Nutr Soc. 2017:76:427-36.

8. Parletta N, Milte CM, Meyer BJ. Nutritonal modulation of cognitive function and mental health. J Nutr Biochem. 2013;24:725-43.

9. Rahimi-Ardabili HRR, Vartanian LR, McLeod L, Zwar N. A systematic review of the efficacy of interventions that aim to increase self-compassion on nutrition habits, eating behaviours, body weight and body image. Mindfulness. 2018;9(2):388-400.

10. Bandura A. Human agency in social cognitive theory. Am Psychol. 1989:44(9):1175-84.

11. Bandura A. Health promotion by social cognitive means. Health Educ Behav. 2004;31(2):143-64.

12. Lubans D, Plotnikoff RC, Morgan PJ. Explaining dietary intake in adolescent girls from disadvantaged secondary schools. A test of social cognitive theory. Appetite. 2012;58:517-24.

13. Bere EKK. Correlates of fruit and vegetable intake among Norwegian school children: parental and self-reports. Public Health Nutr. 2004;7(8):991-8.

14. Levers-Landis CBC, Drotar D, Morgan L, Trapl E, Kwoh K. Social support, knowledge, and self-efficacy as correlates of osteoporosis preventive behaviors among preadolescent females. J Pediatr Pyschol. 2003;28(5):335-45.

15. Frenn MMS, Bansal NK. Stage-based interventions for low-fat diet with middle school students. J Pediatr Nurs. 2003;18(1):36-45.

16. Fitzgerald A, Heary C, Kelly C, Nixon E, Shevlin M. Self-efficacy for healthy eating and peer support for unhealthy eating are associated with adolescents' food intake patterns. Appetite. 2013;63:48-58.

17. Maciejewski PPH, Mazure C. Self-efficacy as a mediator between stressful life events and depressive symptoms. Br J Psychiatry. 2000;176:373-8.

18. Clum GARJ, Broussard M, Johnson C, Webber LS. Associations between depressive symptoms, self-efficacy, eating styles, exercise and body mass index in women. J Behav Med. 2014;37:577-86.

19. Milligan RKBV, Beilin I, Richards J, Dunbar D, Spencer M, Balde GMP. Health-related behaviours and psycho-social characteristics of 18 yearold Australians. Soc Sci Med. 1997:45(10):1549-62.

20. Jaser SS, Holl MG, Jefferson V, Grey M. Correlates of depressive symptoms in urban youth at risk for type 2 diabetes mellitus. J Sch Health. 2009;79(6):286-92.

21. Nolen-Hoeksema S. Gender differences in depression. In: Gotlib and Hammen, editor. Handbook of depression. New York: The Guilford Press; 2002. p. 492-509

22. Kuczmarski MFCA, Hotchkiss L, Cotugna N, Evans MK, Zonderman AB. Higher HEl-2005 scores associated with reduced symptoms of depression in an urban population: findings from the healthy aging in neighbourhoods of diversity across the life span (HANDLS) study. J Am Diet Assoc. 2010:110(3):383-9.

23. Jacka FNKP, Leslie ER, Berk M, Patton GC, Toumbourou JW, Williams JW. Associations between diet quality and depressed mood in adolescents: results from the Australian Healthy Neighbourhoods Study. Aust N Z J Psychiatry. 2010;44:435-42.

24. Ball K, Cleland V, Salmon J, Timperio AF, McNaughton S, Thornton L, et al. Cohort profile: the resilience for eating and activity despite inequality (READI) study. Int J Epidemiol. 2013:42:1629-39.

25. Cuco G, Fernandez-Ballart J, Sala J, Viladrich C, Iranzo R, Vila J, et al. Dietary patterns and associated lifestyles in preconception, pregnancy and postpartum. Eur J Clin Nutr. 2006;60:364-71.

26. Andresen EM, Malmgren JA, Carter WB, Patrick DL. Screening for depression in well older adults: evaluation of a short form of the CES-D (Center for Epidemiologic Studies Depression Scale). Am J Prev Med. 1994;10:77-84

27. Andresen EM, Byers K, Friary J, Kosloski K, Montgomery R. Performance of the 10-item center for epidemiologic studies depression scale for caregiving research. SAGE Open Med. 2013. https://doi.org/10.1177/2050312113 514576. 
28. Boey KW. Cross-validation of a short form of the CES-D in Chinese elderly. Int J Geriatr Psychiatry. 1999;14:608-17.

29. Cheng ST, Chan ACM. The center for epidemiologic studies depression scale in older Chinese: thresholds for long and short forms. Int I Geriatr Psychiatry. 2005;20:465-70.

30. Irwin M, Artin KH, Oxman MN. Screening for depression in the older adult: criterion validity of the 10-item center for epidemiological studies depression scale (CES-D). Arch Intern Med. 1999;159(15):1701-4.

31. IBM Corp. IBM statistical package for the social sciences (SPSS) statistics version 26. 2019.

32. H G, V C. P-values, P-values everywhere!. N Z Vet J 2018;66(2):55-56.

33. Craig CL, Al M, Sjostrom M, Bauman AE, Booth ML, Ainsworth BE, et al. International physical activity questionnaire (IPAQ): 12-country reliability and validity. Med Sci Sports Exerc. 2003;35(8):1381-95.

34. Williams RL. A note on robust variance estimation for cluster-correlated data. Biometrics. 2000;56:645-6.

35. Gunasekara FIRK, Carter K, Blakely T. Fixed effects analysis of repeated measures data. Int J Epidemiol. 2014;43(1):264-9.

36. WHO. Obesity: preventing and managing the global epidemic. Report of a WHO consultation. WHO technical report series 894. Geneva: World Health Organization; 2000.

37. Nezami BT Lang W, Jakicic JM, Davis KK, Polzien K, Rickman AD, Hatley $K E$, Tate $D F$, The effect of self-efficacy on behavior and weight in a behavioural weight loss intervention health Psychol. 2017;16. https://doi.org/ 10.1037/hea0000378.

38. Abusabha R, Achterberg C. Review of self-efficacy and locus of control for nutrition-and health-related behavior. J Am Diet Assoc. 1997;97:10.

39. Firth J, Ward P, Stubbs B. Editorial: lifestyle psychiatry. Front Psychiatry. 2019;10:597.

40. Kavanagh DJBG. Mood and self-efficacy: impact of joy and sadness on perceived capabilities. Cogn Ther Res. 1985;9(5):507-25.

41. Marx W, Jacka F, O'Neil A. Lifestyle-based mental health care in psychiatry: translating evidence into practice. ANZJP. 2021;55(7):641-43.

42. Agurs-Collins T, Fuemmeler BF. Dopamine polymorphisms and depressive symptoms predict foods intake. Results from a nationally representative sample. Appetite. 2011;57:339-48.

43. Konttinen H, Mannisto S, Sarlio-Lahteenkorva S, Silventoinen K, Haukkala A. Emotional eating, depressive symptoms and self-reported food consumption. A population-based study. Appetite. 2010;54:473-9.

44. Appelhans BM, Whited MC, Schneider KL, Ma Y, Oleski JL, Merriam PA et al. Depression severity, diet quality, and physical activity in women with obesity and depression. J Acad Nutr Diet. 2012;112:693-8.

45. Anton S, Miller PM. Do negative emotions predict alcohol consumption, saturated fat intake, and physical activity in older adults? Behav Modif. 2005;29(4):677-88.

46. Darnton-Hill I. Psychosocial aspects of nutrition and aging. Nutr Rev. 1992;50(12):476-9.

47. Anekwe TD, Rahkovsky I. Economic costs and benefits of healthy eating Curr Obes Rep. 2013;2:225-34

48. Ryden P, Sydner YM, Hagfors L. Counting the cost of healthy eating: a Swedish comparison of Mediterranean-style and ordinary diets. Int J Consum Stud. 2008;32(2):138-46.

49. Targum SD, Fava M. Fatigue as a residual symptom of depression. Innov Clin Neurosci. 2011;8(10):40-3.

50. Opie RS, Ball K, Abbott G, Crawford D, Teychenne M, McNaughton SA. Adherence to the Australian dietary guidelines and development of depressive symptoms at 5 years follow-up amongst women in the READI cohort study. Nutr J. 2020;19(30). https://doi.org/10.1186/ s12937-020-00540-0.

51. Li YLM, Wei Y, Sun L, Zhang J, Zhang H, Li B. Dietary patterns and depression risk: a meta-analysis. Pyschiatry Res. 2017;253:373-82.

52. Parletta $N$, Zarnowiecki $D$, Cho J, Wilson A, Bogmolova S, Villani A, et al. A mediterranean-style dietary intervention supplemented with fish oil improves diet quality and mental health in people with depression: a randomized controlled trial (HELFIMED). Nutr Neurosci. 2017;22(7):474-87.

53. Vidgen HA, Gallegos D. Defining food literacy and its components. Appetite. 2014;76:50-9.

54. Adam JFL. Depression, self-efficacy and adherence in patient with type 2 diabetes. J Nurse Pract. 2014;10(9):646-52.

55. Nikolaus CJ, Loehmer E, Jones A, An R, Khan NA, McCaffrey J. Use of survival analysis to predict attrition among women participating in longitudinal community-based nutrition research. J Nutr Educ Behav. 2019;51(9).

56. Australian Bureau of Statistics. National Health Survey: first results - Australia 2017-18. Canberra: ABS 4364.0.55.001; 2018.

57. Hahn-Holbrook J, Cornwell-Hinrichs T, Anaya I. Economic and health predictors of national postpartum depression prevalence: a systematic review, meta-analysis, and meta-regression of 291 studies from 56 countries. Front Psychiatry. 2018;8(248). https://doi.org/10.3389/fpsyt.2017. 00248.

58. Baskin R, Hill B, Jacka FN, O'Neil A, Skouteris H. The association between diet quality and mental health during the perinatal period: a systematic review. Appetite. 2015;9:41-7.

59. Lewinsohn PMSJ, Roberts RE, Allen NB. Center for Epidemiological Studies-Depression Scale (CES-D) as a screening instrument for depression among community-residing older adults. Psychol Aging. 1997;12:277-87.

60. Zhang WOBN, Forrest II, et al. Validating a shortened depression scale (10 item CES-D) among HIV-positive people in British Columbia, Canada. PLoS One. 2012;7(7):e40793.

\section{Publisher's Note}

Springer Nature remains neutral with regard to jurisdictional claims in published maps and institutional affiliations.
Ready to submit your research? Choose BMC and benefit from:

- fast, convenient online submission

- thorough peer review by experienced researchers in your field

- rapid publication on acceptance

- support for research data, including large and complex data types

- gold Open Access which fosters wider collaboration and increased citations

- maximum visibility for your research: over 100M website views per year

At BMC, research is always in progress.

Learn more biomedcentral.com/submissions 